\title{
Environmental Impact Assessment of Human Error to Exhaust Toxic Gases and Oil Spilling for Prevention of Natural Disaster Through Fault Tree Analysis
}

\author{
Manoj Singh Yadav, Dr. R K Mandloi, Ishpreet Singh \\ Mechanical Engineering Department, \\ National Institute of Technology, Bhopal, \\ 462003, India
}

\begin{abstract}
Gasoline is a extremely flame retardant and poisonous substance. Once fuel evaporates, The emitted vapours and the contaminants produced while Burning oil (carbon monoxide, oxides of ammonia, particulate matter and unburnt hydrocarbons) results in pollution pollutants.. Burning oil does also contain carbon dioxide, a greenhouse gas. Environmental Impact Assessment (EIA) is a process for assessing the likely impacts and risks project or development, taking into accounts both positive and negative effects socio-economic, cultural and living organism-health impacts. In India '2020 Assam gas and oil leak', '2017 Ennore oil spill', '2010 Mumbai oil spill' after that There are thousands of people rescued and National Disaster Response Force was deployed in the region. Chemical leaks at sea are usually much more harmful than accidents on shore, as they can extend in a thin oil slick over hundreds of nautical miles, and will blanket beaches with a thin oil coating. They are capable of destroying seabirds, mammals, shellfish and other species they protect. Chemical releases on ground are harder to control because a toxic earth barrier can be immediately bulldozed around the spill site so the chemical spreads, so surface species can more effectively stop it. Environmental impact assessment (EIA) is the essential to effective monitoring of construction infrastructure for the environment. This is used to predict, measure and raising a project's environmental and social risks. This study proposes an applied approach for the examination of fault tree, which Provides opportunities for the qualitative and quantitative incorporation information for environment impact assessment for any industry or project. This literature review gives an idea about using of FTA method for environment impact assessment. The research findings illustrates that FTA method can be significantly used for the EIA.
\end{abstract}

Key words: EIA Norms, Fault Tree Analysis, Environment Impact Assessment, Boolean Logic, Socio-Economic Impact Assessment, Natural Disaster, GM Organism

\section{INTRODUCTION:}

Eventually, The environmental factors are growing increasingly important nowadays. We consider natural resources and the very basis of human society. The main concern among these is the availability of raw materials and energy. Although the availability of fossil fuels such as oil or gas could deteriorate in the next several decades, dependence on these fuels continues to be quite risky. In reality, to show an ecological responsibility, companies should evaluate and that their ecological damage. The public interest is increasingly stressing an environmentally friendly management through way of special raw materials and by waste. Environmentally friendly products or inventions may therefore also represent a competitive advantage. Environmental Impact Assessment ( EIA) is the systematic method used to assess the (positive or negative) environmental effects of a proposal, strategy, initiative, or activity prior to the decision to go ahead with the planned intervention. Formal effects reviews can be regulated by regulatory regulations on public engagement and decision-making reporting, which may be subject to judicial examination. The environmental impact assessment (EIA) is a procedure for assessing the likely environmental impact of a proposed project or planned development, taking into account the socio-economic, cultural and health effects, depending on each other, both beneficial and negative. There many more definition is given such as by UNEP explains the framework of an environmental impact assessment ( EIA) utilized Until taking judgments on environmental, social and economic assessment effects of a proposal. This aims at forecasting Environmental Impacts infrastructure preparation and design at an early level, identifying ways and means to minimize adverse impacts, designing designs to fit the local community and providing the forecasts and alternatives for decision-making EIA is an inherently complex, multi-dimensional process. Maybe because of this complexity, the implementation of the EIA is not entirely satisfactory (e.g. Moon, 1998). New innovations and methods may be needed to improve the EIA process. Using a gallon of fuel (which includes no ethanol) produces nearly 19.6 pounds of carbon dioxide. Net U.S. carbon dioxide emissions from the burning of aircraft and automotive fuels were around 1.142 million metric tons in 2018, or around 22 percent of the entire U.S. energy-related carbon dioxide emissions. In India emits around 3 gig tons (Gt) of CO2eq annually of greenhouse gases; about two and a half tons per person, which is half the world average. The country accounts for 7 per cent of global emissions. Many countries to emit the gases for generation of energy and it's also depend upon population of their countries.

In fact, the EIA process is evolving since its adoption to analyze the environmental impact of development projects. Fault Tree Analysis (FTA) is a top-down deductive fault analysis that analyzes a system's undesirable condition using Boolean logic to 
incorporate a sequence of lower-level events. FTA incorporates the Boolean logic principle, which allows for the development of a set of True / False claims. This approach often offers useful troubleshooting knowledge when used to problem solving, and FTA diagrams also use probability of failure at each stage, from modules and applications to the unexpected top-level case. This literature review provides a systemic approach for environmental assessment by use FTA diagram and methodology of constructing the FTA diagram.

\section{ENVIRONMENTAL IMPACT ASSESSMENT (EIA):}

Environmental assessment (EA) is an environmental impact evaluation (positive negative) of a proposal, strategy, system or existing activity prior to the decision to continue with the planned action. The word "Environmental Impact Assessment" (EIA) is typically used in this sense when applying by entities or organizations to particular initiatives and the phrase "Strategic Environmental Assessment" (SEA) refers to strategies, plans and programs most frequently introduced by state bodies[1][2]. This is an environmental monitoring mechanism that is part of planning development and decision-making [3]. Environmental reviews must be regulated by regulatory statutory guidelines on citizen engagement and decision-making reporting, which can be subject to judicial scrutiny. The aim of the assessment is to insure that policy makers recognize the effect on the ecosystem while determining whether or not to continue with a project. The International Association for Impact Assessment (IAIA) describes an environmental impact assessment as "the method of defining, forecasting, evaluating and minimizing the biophysical, financial, and other related impacts of construction projects before substantive decisions and commitments are made"[4]. EIAs are unusual in that they do not allow conformity to a preset environmental result, but instead enable decisionmakers to account in their decisions for environmental principles and to explain such decisions in the light of comprehensive environmental assessments and public feedback on possible environmental impacts [5].

Environmental impact studies started in the 1960s, as part of growing understanding of the environment. EIAs included a professional review meant to lead to a more informed decision making process. Environmental impact evaluations in the United States received legal recognition in 1969, with the National Environmental Protection Act being passed. EIAs are gradually being used around the planet. Each year, the number of environmental assessments submitted "has greatly exceeded the number of more stringent environmental impact statements (EIS)"[6]. The environmental evaluation is a 'mini-EIS intended to include adequate details to allow the organization to evaluate if a full-blown Environmental Impact Statement (EIS) will be prepared. '[7][8] EIA is an undertaking conducted to establish the effect that will be created before construction takes place.

EIA is recognised in a wide range of international conferences, treaties and agreements, including basic environmental assessment (EA): The Convention on Tran boundary Environmental Impact Assessment; Convention on Global Importance of Wetlands; Convention on Access to Data, Community Interest in Decision-making and Environmental Justice; United Nations Framework Conference on Climate Change; UN convention on climate change the Rule of the Sea; Protocol to the Antarctic Treaties on Environmental Security.

\section{IN ENVIRONMENTAL IMPACT (EI) PROBLEMS OF THREAT AND CAUSES:}

3.1 Assam gas and oil leak: It occurred because the oil well had failed pressure systems. Thousands of people were evacuated, and several villages. Deaths of several aquatic animals have been reported in nearby area. The gas is now flowing uncontrollably as from 5 June 2020. It also impacts biodiversity in surrounding areas like several endangered animals in surrounding Dibru-Saikhowa National Park. It is also reported that certain harmful chemicals are also released, creating potential for further damage.

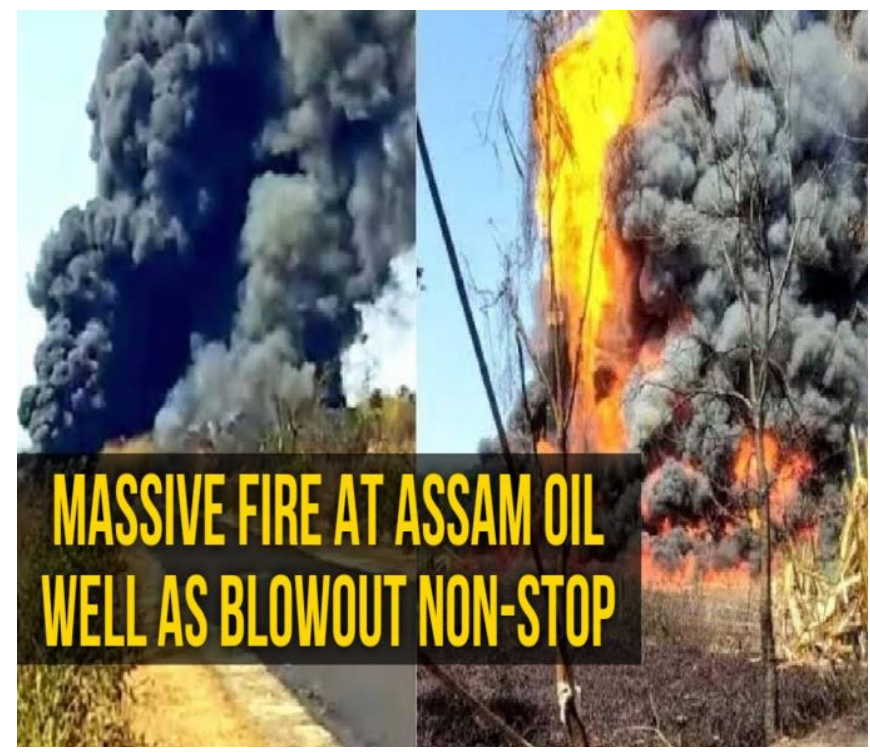


3.2 Vizag gas leak: The Visakhapatnam gas spill, also known as the Vizag gas leak, was an industrial incident that happened at the chemical plant LG Polymers in the R. R. Venkatapuram neighborhood village Gopalapatnam, situated at the outskirts of Visakhapatnam, Andhra Pradesh, India, early in the morning of 7 May 2020.

The spill came from one of two chemical tanks left unattended as a consequence of the COVID-19 lockdown from March 2020. The malfunctioning of the refrigerating unit of the tank resulted in an increase in temperature, causing evaporation of the liquid chemical, which is suspected to be styrene.

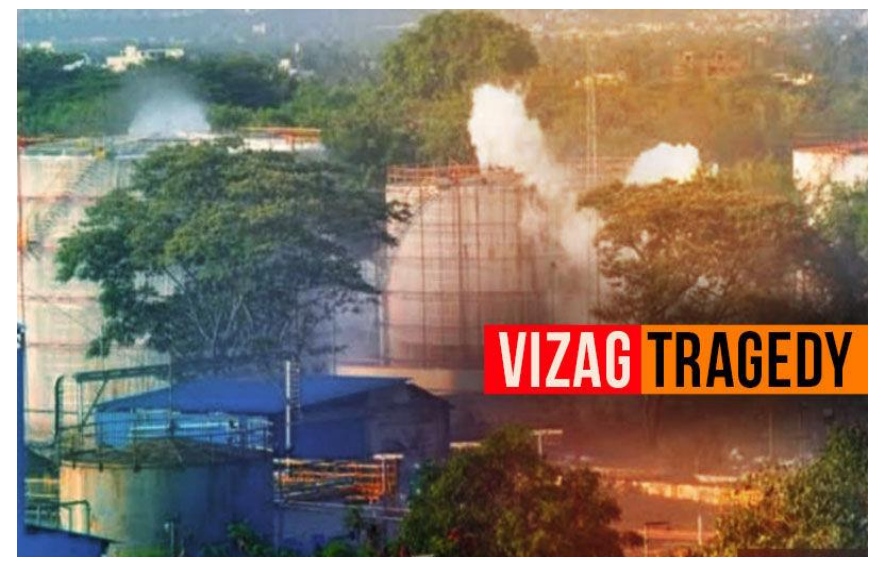

3.3 Ennore oil spill: In January 2017, two containers, the Dawn Kanchipuram and the BW Maple, collided off Ennore triggering an oil spill of 251, 46 tonnes. An inquiry by the Shipping Directorate-General has concluded that the primary cause of the crash was human error and exhaustion among crew.

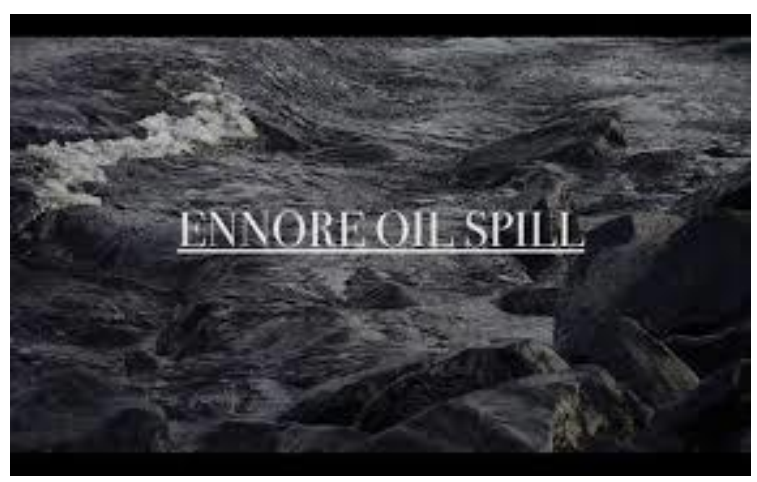

3.4 Mumbai oil spill: On August 2010, two container ships collided off the Mumbai coast triggering an oil spill that was distributed quickly across the coasts of Maharashtra. After entering incoming MV Khalijia, MSC Chitra ruptured its tank and ran aground at Colaba, past Prongs Reef Lighthouse. The vessel had around 1,200 tons of fuel oil in its tanks, 800 tons of which leaked into the Arab Sea until two days later the leaks could be fixed. The collision hurt prows of Khalijia. Chitra tilted precariously at an angle of 75 degree which caused 400 containers to fall off on its deck and float into the water. Any of those tanks had pesticides containing poisonous organophosphates.

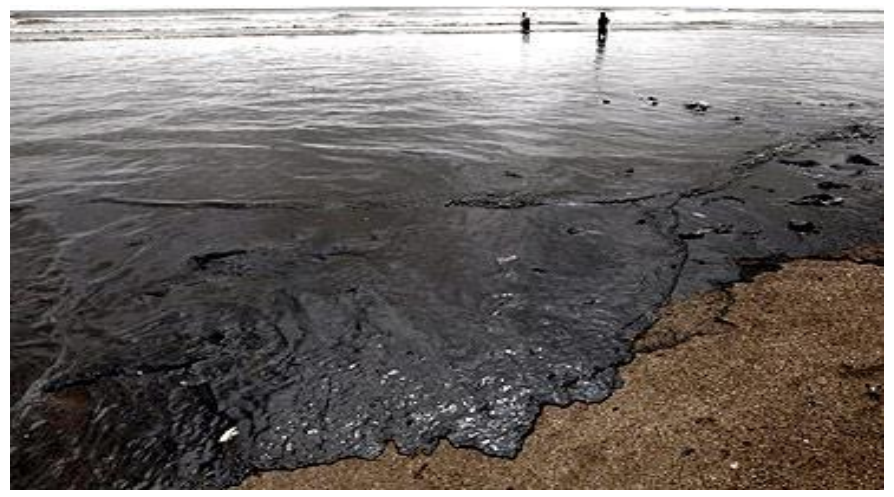


3.5 Bhopal gas tragedy: In the night of 2-3 December 1984, the Bhopal tragedy, also identified as the Bhopal gas disaster, At Union Carbide India Limited (UCIL) pesticide factory in Bhopal, Madhya Pradesh, India, a gas leak occurred. It's called one of the country's biggest economic environmental disasters.

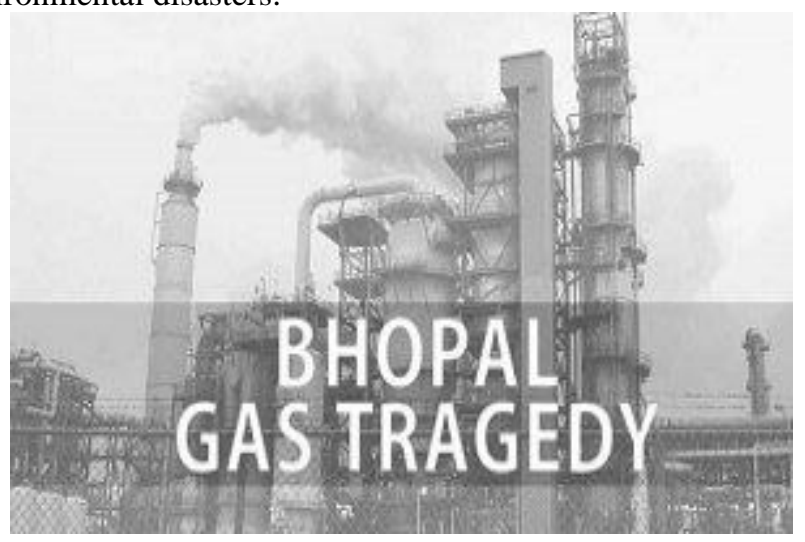

I mentioned above event just in India, but there was something occurring in the worlds every day that harms the existence of these kinds of EI problems. Many accidents involuntarily do without worrying about the effects of environmental condition, such as developing missiles like nuclear, hydrogen atom bomb, which is the explanation for creating global warming issues.

HRA is the systematic identification, modelling, and probabilistic quantification of human error. HRA may be qualitative, requiring just the detection and analysis of the mistake; or quantitative, by also calculating a likelihood of human error (HEP) for a specific function. Human error is significant because it has implications such as contributing to a hardware device malfunction, or leading to injuries or death. Human error may therefore have major implications for health or the climate. HRA attempts to establish the human danger variable which, when used, function as the framework for the avoidance which reduction of human errors.

Offshore oil and gas projects contained dangers.

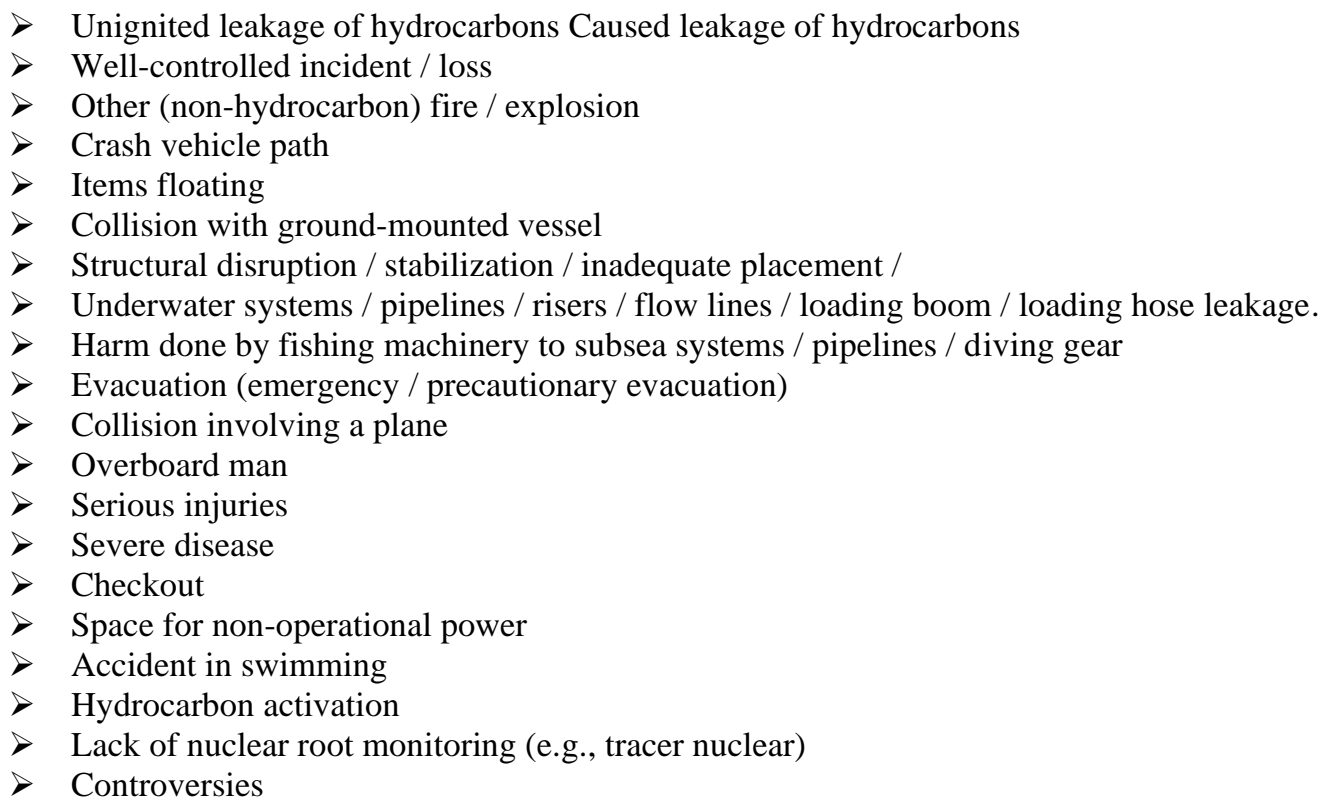

Most of the EI problems induced by human carelessness because minor fault does not take the significantly and in the end these minor fault reach into major disaster, if maintain the instrument properly to predict the factor of safety provided then some incident can be prevented. Eventually inspection of system must require stopping that type of accident for affected the environment and living organisms.

3.6 Australian bushfire season 2019-20 colloquially called the Black Summer is a period of particularly destructive bushfires in Australia. Hot, dry environment coupled with continuing drought and powerful winds produced ideal conditions for rapid spread of fire. Bushfires can come from both human activity and natural causes-the predominant natural source being the lightning 


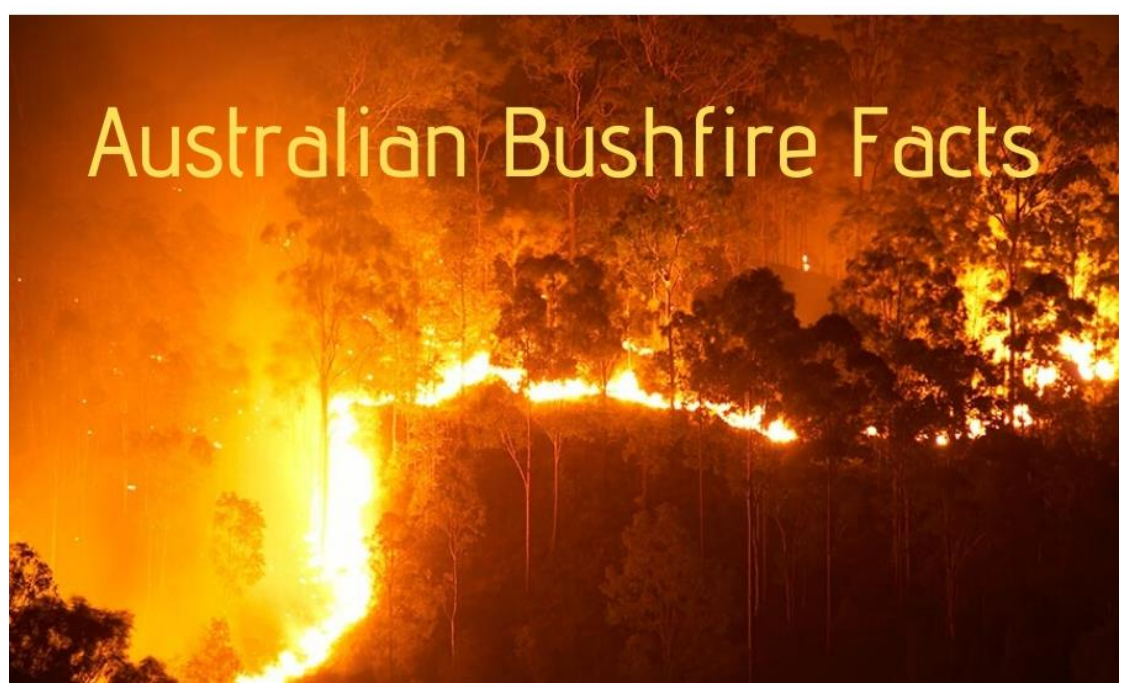

3.7 One of the global pandemics like COVID-19 that is becoming our planet's threat, it seems like the circumstance of the sort of world war. The pandemic is often triggered by human error.

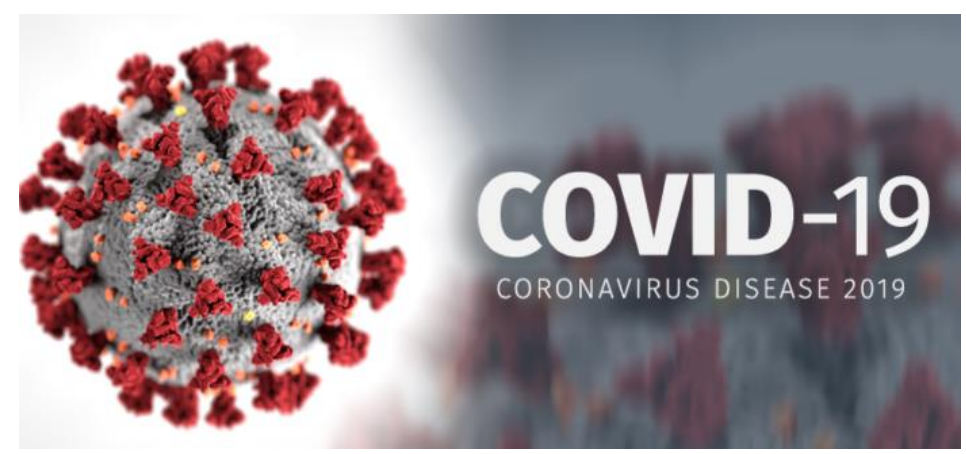

As per environment point of view something has affected positive in that Owing to extreme air circumstances, the biggest breach in the ozone layer that stretches about 1 million square kilometres above the Arctic has filled. Scientists first found the void earlier this year, in March. The European Centre for Medium-Range Weather Forecasting (ECMWF) confirmed the Copernicus Climate Change Service (C3S) and the Copernicus Atmospheric Surveillance Services (CAMS) the development. But the hole closing has little to do with rising emission rates in the midst of the lockout. This is because of the polar vortex, high-altitude winds that carry freezing weather to the Polar Regions. Such holes in the ozone layer are very frequent in the South Pole over the Antarctic, especially between July and September, however at this point the ozone layer hole over the Arctic at this time was unusual.

\section{ARCTIC OPENING}

A rare and record ozone hole has formed over the Arctic. An opening in the ozone layer appears each spring over the Antarctic, but the last time this phenomenon was seen in the north was in 2011.

\section{March 2019}

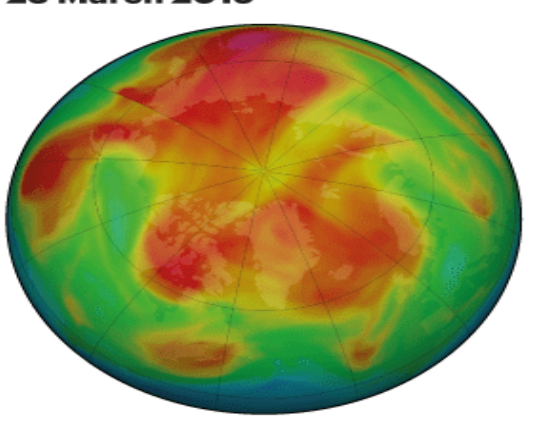

23 March 2020

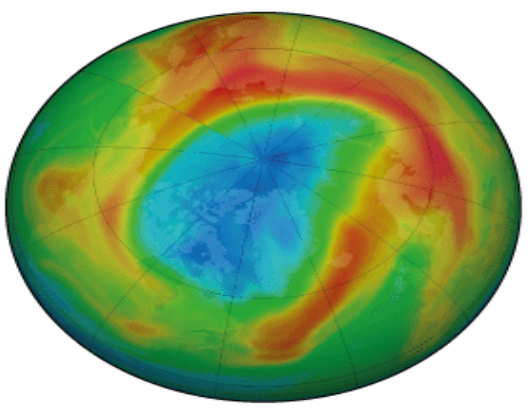

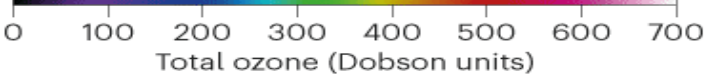

(c)nature 


\section{THE INGREDIENTS OF AIR POLLUTION EFFECTS DUE TO EMISSION OF GASES FROM VEHICLES:}

During their life cycle, automobiles, trucks and buses generate air emissions, including pollutants released during automobile service and fuel processing. More pollutants are concerned with fuel production and storage and, to a smaller degree, the produce and disposal of automobiles. Temperature of exhaust gas (EGT) is critical for the operation of an internal combustion engines catalytic converter. This can be calculated using a temperature scale for exhaust gas. EGT also provides a indicator of engine safety in gas turbine engines. Air pollution from automobiles, trucks and buses is broken down into primary and secondary pollution. Main emissions emit directly into the environment; secondary emission comes from chemical reactions in the atmosphere between contaminants. Fetuses, unborn children and individuals with chronic diseases are highly vulnerable to air pollutant effects. The following are the major motor-vehicle pollutants:

4.1 Particulate matter (PM): The soot that is used in car emissions is one Particulate shape of matter. Tiny particles less than one-tenth of a human hair's diameter present a major danger to public health because they may penetrate far into the lungs. PM may be a primary pollutant from hydrocarbons, nitrogen oxides, and sulphur dioxides or a secondary contaminant. Diesel exhaust is a major polluting source to PM.

4.2 Organic Volatile Compounds (OVCs): Such contaminants combine and nitrogen oxides creating ground level ozone in the centre of the day, a primary component in smog. Although beneficial in the upper atmosphere, this gas irritates the respiratory system at ground level, causing nausea, diarrhea and decreasing lung power. VOCs generated by vehicles, Lorries and buses including Benzene, acetaldehyde and 1, 3-butadiene harmful surface emissions different cancer types.

4.3 Nitrogen oxides (NOx): At ground level these pollutants contain ozone and (secondary) particulate matter. NOx, Also harmful as a chemical pollutant, it may cause inflammation of the lungs and weaken the body's protection against respiratory disorders such as pneumonia and flu.

4.4 Carbon monoxide (CO): This odorless, colorless, and poisonous gas is created by the combustion of fossil fuels like petrol and Is produced mainly by motor vehicles and trucks. When inhaled, the CO extracts oxygen from the blood, heart and other important organs.

4.5 Sulphur dioxide (SO2): Power plants and motor vehicles produce this pollutant by combustion of sulphur-containing fuels, particularly diesel and coal. Sulphur dioxide, like other air contaminants, can respond to small particles in the environment and present the greatest health danger to young children and asthma.

4.6 Greenhouse gases: Cars also emit contaminants that lead to global climate change, especially carbon dioxide. Furthermore, automobile, vehicle, and bus emissions account for more than one-fifth of the overall global warming output in the United States; transport, which involves airplanes, cars, and ships, accounts for around thirty per cent of all heat-trapping gas emissions.

Gases Emission from thermal power plant: Thermal power plants are one of the most powerful artificial sources of poisonous gases and particulate matter production. Emissions of toxins such as $\mathrm{NOx}, \mathrm{SOx}, \mathrm{CO} 2, \mathrm{CO}, \mathrm{PM}$, industrial compounds and polycyclic aromatic hydrocarbons are generated by fossil fuel power plants. Fly ash Coal fly ash is lightweight fragments collected by electrostatic precipitators in waste steam, and coal-fired power plant bag rooms. Fly ash is very fine with cementlike properties, and has long been used in construction as an ingredient, but not without controversy.

If carbon emissions were more than carbon sinks at this period, the pace of environmental regeneration would be very sluggish, but in order to conserve the ecosystem, we will have to create for carbon sink like as plantation, Lake and We should be also reduced deforestation.

The following catastrophe was due to some interference of natural and some human error, but my conclusion was that after reviewing similar analyses of the literatures. Environmental risk evaluation is also widely regarded as an important part of rational decision-making in its simplest form. Many industries like as automobile, chemical, some power plant in night time ESP Device off for want to more profit without impact consideration of environment. Government of India lack behind it because this effect is not immediately. Several citizens issue the climate knowledge is limited and overlooked. Gradually natural resources affected and Several Environmental organizations have launched a movement requesting the removal of the Draft. In the face of such movements, the Indian government has resorted to banning/blocking such groups' websites. I saw some city most polluted and it's behind the reason using by diesel vehicle and below BS III norms engine. If using BS Norms above the IV or BS-IV NORMS so in which low particulate matter and low unburnt hydrocarbon emitted. Hence, e-vehicles, green energies mainly used to reduce emissions, produce solar power, wind power, and other engineering resources that do not harm the atmosphere and living stuff. For boost the Sustainable Development So India's Ministry of Environment, Forests and Climate Change (MoEFCC) has spent a lot of research in the environmental risk assessment of India. The major laws in place are the Water Act (1974), the Indian Wildlife Act (1972) and the Environment (Emissions Control and Regulation) Act (1981) and the Environment (Protection) Act (1986) and the Biological Diversity Act (2002)[55]. 


\section{FAULT-TREE ANALYSIS:}

Fault Tree Analysis (FTA) was first developed by Bell Laboratories and is one of the most commonly used techniques for evaluating device stability, repair and protection. It is a deductive method that distinguishes the specific combinations of hardware and software faults and human mistakes that can trigger unintended events at device level (so-called key events). The deductive reasoning starts with a general assumption and then, by constructing a rational structure called the fault tree, attempts to establish the precise triggers of the inference. This is often dubbed a top-down strategy. Using fault tree analysis the primary goal of an examination of the fault tree is to recognize the possible triggers of device faults before they eventually arise. This may also be implemented using empirical or predictive approaches to determine the probability of the maximum occurrence. These calculations include quantitative information about the reliability and maintainability of the system, such as the probability of failure, the failure rate and the repair rate. The specific events should be identified in a fault tree, and the likelihood of the Unwanted Top Event (UTE), the oil spill, can be determined if the risks of the fundamental events are established. For example of titanic ship disaster, the fault tree analysis for, this emphasizes the seriousness of failure sequences leading to the well blowout.

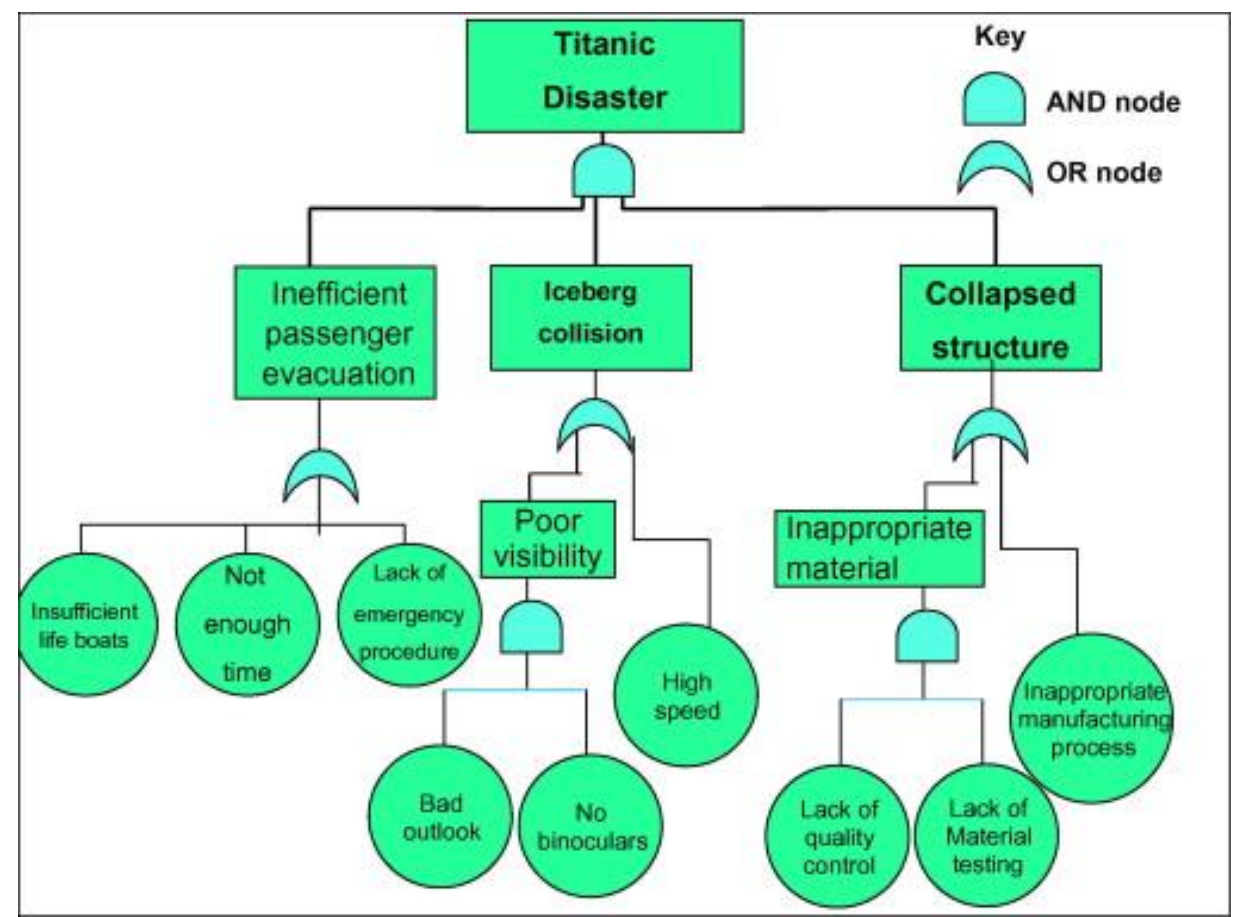

6. Fault tree construction: In which industrial sector problem can be reduced comes under human to complete a full free trade agreement with respect to EIA.

$>$ Set the error state and notice the error at the top level.

$>$ To assess the potential causes for the mistake, using scientific knowledge and qualified judgement. Note, these are components of the second level, since they are only below the top level mistake in the tree view.

$>$ Disassemble each item at the lower level with additional doors. Find the relationships between the entities that agree to use a "either" or "or" logical port.

$>$ Finalize the diagram and study it in detail. Just one basic error will break the chain: person, hardware or software.

$>$ Determine the likelihood of incidence for increasing of the lower level components where necessary and measure the statistical odds from top to bottom.

7. METHODOLOGY OF FAULT-TREE

In this study, an applied framework of the FTA technique to assess and evaluate the environmental effects due to a given project or plane. Although the EIA cycle has different phases, such as,

7.1 Environment Screening.

7.2 Environment Scoping.

7.3 Fault Prediction and mitigation.

7.4 Management and monitoring.

7.5 Audit. 


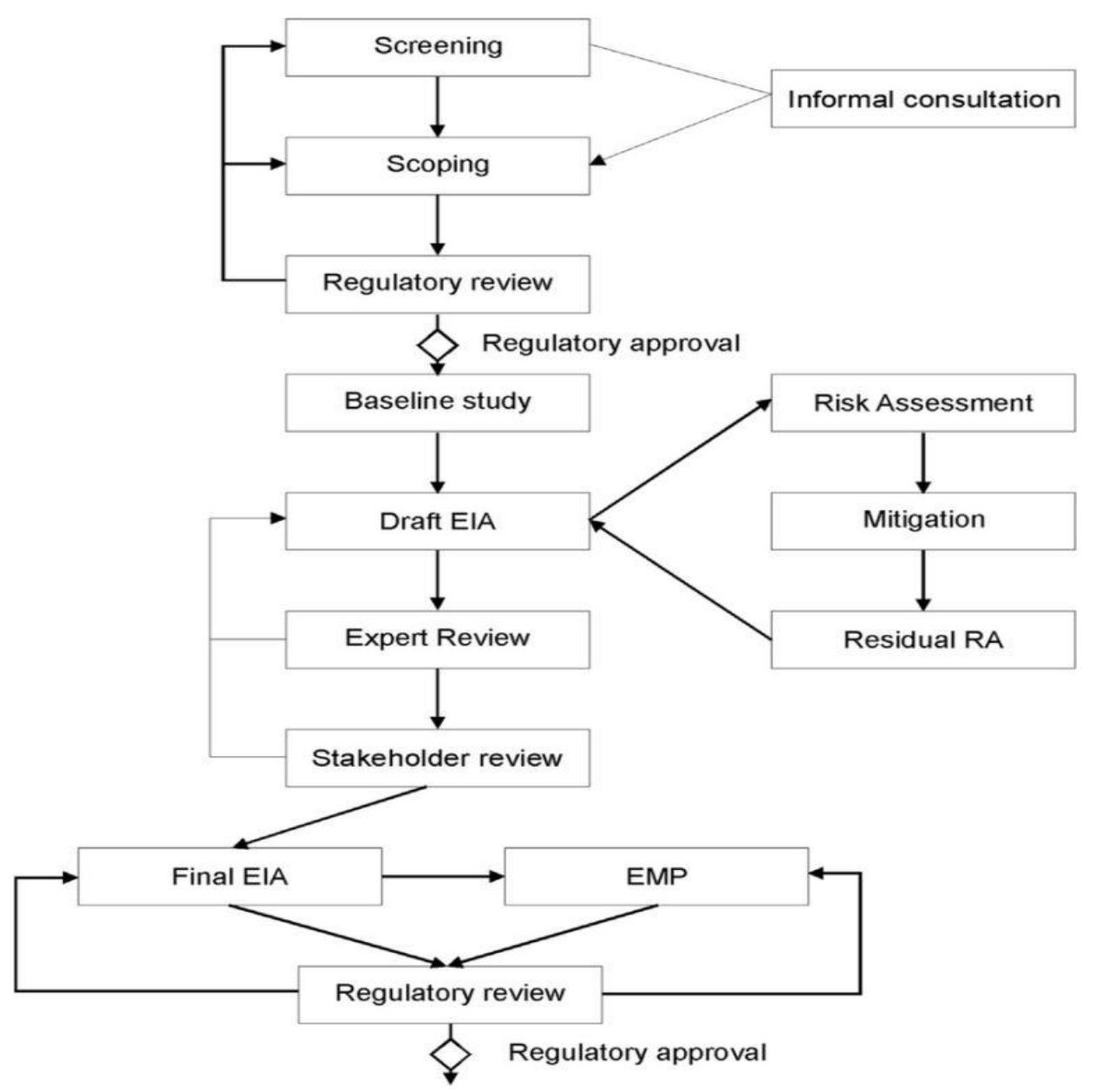

Whereas the FTA review is made up of four phases.

$>$ Name of the program

$>$ Design of defective tree

$>$ Qualitative Review

$>$ Comprehensive appraisal

This literature review suggest to combine the FTA methodology to EIA process for any industry or organization to have a Hence these can be done easily by knowing the FTA diagram for the project or industry. And this knowledge of assessment can help in determining different stages of failure and fault.

The current environment situation: An increasing world, global warming and biodiversity depletion have a major effect on our climate. In 2050 this world should be home to 9.5 billion citizens. Which means the global population is projected to expand by 3 billion in fewer than 50 years. Feeding these citizens would require major improvements in food growth, delivery and security. Unfortunately there is no standardized distribution of the cropland and people. For example, China has just 1.4 percent of the world's agricultural land but 20-25 percent of the world's people. This problem is further compounded by declining cropland due to deforestation, less natural resources, less energy, and a decreased farm-work people. The loss of wildlife and trees, and increased consumption of coal and oil, has culminated in a gradual rise in rates of carbon emissions, contributing to global warming. The average global temperature is expected to increase by $1.4-5.8$ Degree Celsius by 2100 , with rising weather variability. Climate change will dramatically alter weather trends and thus allow citizens to relocate and agricultural practices to move. In turn, a increasing human community is responsible for degradation of the wilderness, water pollution issues and water depletion. The land destruction has contributed to the extinction of several animals. Thus, in order to preserve trees, wetlands and wildlife, it is important to insure that potential food needs only come from currently utilized cropland.

Genetically modified organism (GMO) used to reduce Contamination: Genetically engineered plants or microorganisms play an important part in the removal of agricultural waste, the reduction in contamination of other materials and the prevention of hydrocarbon emissions and oil leakage.

The discussion regarding the effect of genetically modified (GM) crops on the ecosystem is highly complicated, volatile and intensely emotional. When new work is conducted it becomes more difficult. Are genetically engineered crops healthy for the environment? 
$>$ Gene technology includes DNA analysis, genetic engineering and other gene manipulation.

$>$ Genetic engineering refers the artificial manipulation of genes: adding or subtracting genes, or changing the way genes work.

Organisms with artificially altered DNA are referred to as genetically modified organisms (GMOs)

$>$ Gene technologies have great potential to benefit humanity through that is increase crop production, increase livestock production, preventing and fighting disease, reducing pollution and waste, producing new products, detecting and preventing crime.

It is also challenging to determine the environmental effect of GM crops, since several considerations are regarded. Some scientists concentrate on the possible hazards associated with GM crops while others will talk about their potential benefits. Where the problems lay and how we can overcome them?

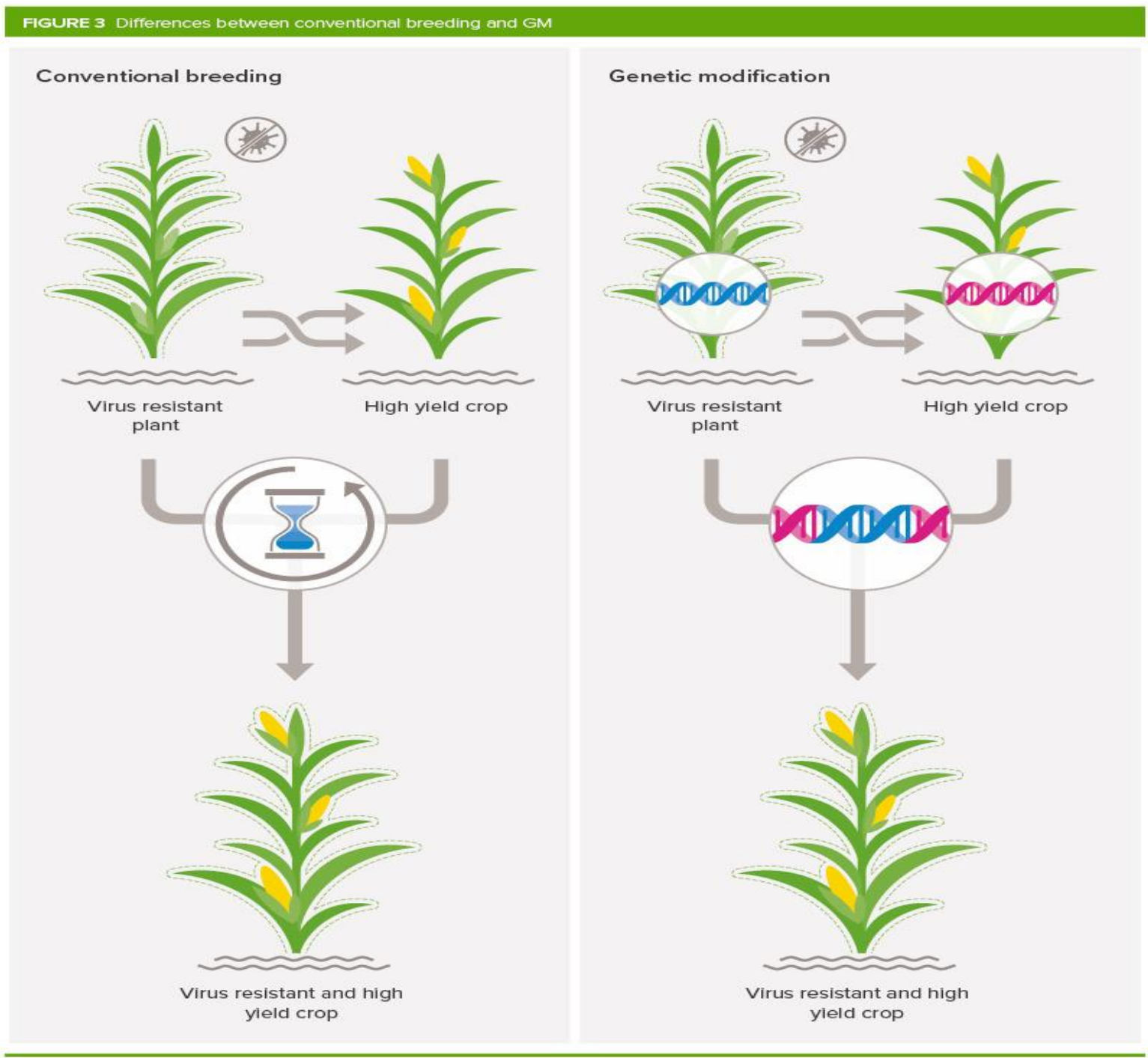

\section{CONCLUSION}

This report provides a conceptual system for identifying and implementing the approach of fault tree analysis to environmental effect evaluation for every organisation i.e. manufacturing industry, power plant building, aeroplane building or any human activity which could harm the environment which subsequently harm the livings. This present study proposes an operational model for EIA for any project or plane or industry by just constructing the FTA diagram for the project or industry. As by drawing the FTA diagram the critical area or system can be easily understood this can help us in assessing the environment impact of project which helps in reducing the impact or harm on ecosystem or livings. Nonetheless, the Challenge may be the difficulty of the set of parameters and sub-criteria for the prospective of FTA diagram. Additional study has to be done to have a complete synergic study of fault and impact on environment. Finally, the present research presents the case industry with an ability to reduce its carbon pollution and, of necessity, the result of this analysis will be important for change the process of EIA effectively and efficiently. Until publication, environmental and ecological issues theoretically related to an assessment of GM 
crops. In addition, to recognise and minimize possible threats and to ensure that GM crops stay safe after implementation, monitoring Post-authorisation and healthy agricultural processes need to be done. Comparisons between GM, organic, and other agricultural activities, including organic farming, will display the relative costs and Benefits of genetically engineered crops.

\section{REFERENCES}

[1] Cheliyan, A. S., and S. K. Bhattacharyya. "Dynamic fault tree analysis of dynamic positioning system using Monte Carlo approach." Safety in Extreme Environments (2019): 1-9.

[2] Shoar, Shahab, Farnad Nasirzadeh, and Hamid Reza Zarandi. "Quantitative assessment of risks on construction projects using fault tree analysis with hybrid uncertainties." Construction Innovation 19.1 (2019): 48-70.

[3] Yazdi, Mohammad, and Esmaeil Zarei. "Uncertainty handling in the safety risk analysis: an integrated approach based on fuzzy fault tree analysis." Journal of failure analysis and prevention 18.2 (2018): 392-404

[4] Brookes, G and P Barfoot. 2018. GM crops: Global socio-economic and environmental impacts 1996- 2016. PG Economics Ltd, UK. p 1-204.

[5] Perry, ED, F Ciliberto, DA Hennessy, and GC Moschini. 2016. Genetically engineered crops and pesticide use in U.S. maize and soybeans. Science Advances 2(8): e1600850. http://advances.sciencemag.org/content/2/8/e1600850.full.

[6] Brinsfield, W. and J. Voskuli, "Focusing the Scope of Fire PRA Human Reliability Analysis Using Top Event Prevention (TEP)," PSA $2015,2015$.

[7] Blanchard, D. P. and R. W. Youngblood, "Risk-Informed Safety Margin Characterization Case Study: Use of Prevention Analysis in the Selection of Electrical Equipment to Be Subjected to Environmental Qualification," PSAM 12, 2014.

[8] Klümper, W and M Qaim. 2014. A Meta-analysis of the impacts of genetically modified crops. PLoS ONE 9(11): e111629. https://doi.org/10.1371/journal.pone.0111629.

[9] Yousfi Steiner, Nadia, et al. "Application of fault tree analysis to fuel cell diagnosis." Fuel Cells 12.2 (2012): $302-309$.

[10] Mentes, Ayhan, and Ismail H. Helvacioglu. "An application of fuzzy fault tree analysis for spread mooring systems." Ocean Engineering 38.2-3 (2011): 285-294.

[11] (1) Bond, A.J., and Morrison-Saunders, a, Re-evaluating sustainability assessment: aligning the vision and the practice. Environmental Impact Assessment Review, 31, 2011.

[12] Sadler, B., et al., 2011. Taking stock of SEA. In: B. Sadler, ed. Handbook of strategic environmental assessment. London: Earthscan, 1-18.

[13] Geum, Youngjung, et al. "Application of fault tree analysis to the service process: service tree analysis approach." Journal of Service Management 20.4 (2009): 433-454.

[14] Volkanovski, Andrija, Marko Cepin, and Borut Mavko. "Application of the fault tree analysis for assessment of power system reliability." Reliability Engineering \& System Safety 94.6 (2009): 1116-1127.

[15] Snell, T., and Cowell, R., 2006. Scoping in environmental impact assessment: balancing precaution and efficiency? Environmental Impact Assessment Review, 26 (4), 359-376.

[16] China urges further protection of arable land, March 23, 2004. http://english.people.com.cn/200403/23/eng20040332_138213.shtml.

[17] Pray, CE, J Huang, R Hu and S Rozelle. 2002. Five years of Bt cotton in China - the benefits continue. The Plant Journal, 31(4):423-430 